standard:0, No swelling:1, Slight redness and swelling;2, Moderate redness and swelling of ankle; 3 , Severe redness and swelling of the entire paw;4, Maximally inflamed limb with involvement of multiple joints ${ }^{[3]}$ ). Day $28-42$, hind foot redness and swelling of the mouse continued to develop and extended to the forefoot. Compared with the normal group, incidence of CIA model group reached 100\%. Day 49, compared with the model group by joint scores, medium-dose group, high-dose group and leflunomide group have Significant differences on CIA model $(p<0.01)$. Compared with the Leflunomide group, low-dose group, medium-dose group and high-dose group have no obvious difference $(p>0.05)$. Compared with the low-dose group, medium-dose group and high-dose group have no difference $(p>0.05)$.

Table 1. Joint scores (mean \pm SD)

\begin{tabular}{lcccc}
\hline groups & $28 \mathrm{~d}$ & $35 \mathrm{~d}$ & $42 \mathrm{~d}$ & $49 \mathrm{~d}$ \\
\hline a & 0 & 0 & 0 & 0 \\
b & $8.05 \pm 1.62$ & $12.40 \pm 2.10$ & $14.68 \pm 1.77$ & $12.33 \pm 1.68$ \\
c & $8.66 \pm 0.14$ & $11.99 \pm 0.23$ & $12.10 \pm 0.23^{\star *}$ & $11.30 \pm 0.22^{\star \star}$ \\
d & $7.90 \pm 0.34$ & $11.40 \pm 0.18$ & $12.80 \pm 0.20^{\star *}$ & $12.00 \pm 0.13$ \\
e & $7.40 \pm 0.23$ & $10.90 \pm 0.13^{\star}$ & $10.40 \pm 0.44^{\star *}$ & $10.60 \pm 0.36^{\star *}$ \\
f & $8.80 \pm 0.24$ & $10.60 \pm 0.30^{*}$ & $11.30 \pm 0.22^{\star *}$ & $8.80 \pm 0.55^{\star \star}$
\end{tabular}

a. Blank group. b. Model group. c. Leflunomide group. d. Low-dose group. e. Medium-dose group. f. High-dose group. Compared with the model group, ${ }^{\star} \mathrm{p}<0.05,{ }^{* *} \mathrm{p}<0.01$.

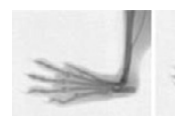

a

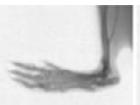

b

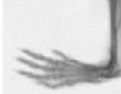

C

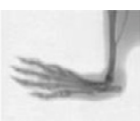

d

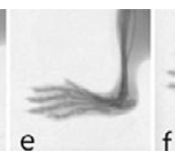

e figure 1. Ankle Joint X-ray

a.blank group b.model group c.leflunomide group d.low-dose group e.medium-dose group f.high-dose group

Conclusions: CIA model has a high morbidity, long duration, macroscopic pathological manifestation and irreversible ankle joint deformation, which is consistent with the progress of human RA disease and pathological damage. Medium-dose of ChuanTengTongBi decoction, high-dose and leflunomide group had inhibitory effect on the progress of arthritis, and the effect of high-dose was better than that of leflunomide group.

References:

[1] Brand, D.D. Rodent models of rheumatoid arthritis. Comp. Med. 55, 114122(2005).

[2] Shen S, Yang Z, Yiyang $\mathrm{H} \mathrm{U}$, et al. The Effect of Tripterygium Wilfordii glycoside on the Expression of CD_4+CD_(25) (high) Regulatory T cells, Th1 and Th2 with IgA Nephropathy[J]. Chinese Journal of Integrated Traditional \& Western Nephrology, 2013.

[3] David D Brand, Kary A Latham, \& Edward F Rosloniec. Collagen-induced arthritis. Nature Protocol.5.1270-1274(2007).

Disclosure of Interest: None declared

DOI: 10.1136/annrheumdis-2017-eular.3396

\section{AB0111 CADMIUM NANOPARTICLES CITRULLINATE INTRACELLULAR CYTOKERATINS: CADMIUM POTENTIALLY LINKS RHEUMATOID ARTHRITIS TO SMOKING AND NUMEROUS WORKING CLASS OCCUPATIONS}

D. Hutchinson ${ }^{1}$, J. Müller ${ }^{2}$, J.E. McCarthy ${ }^{3}$, Y. Gun'ko ${ }^{3}$, N. Verma ${ }^{4}$, X. Bi ${ }^{5}$, L. Di Cristo $^{3}$, L. Kickham ${ }^{3}$ D. Movia ${ }^{3}$ A. Prina-Mello ${ }^{3}$, Y Volkov ${ }^{3}{ }^{1}$ Royal Cornwall Hospital Trust, University of Exeter Medical School, Truro, United Kingdom; ${ }^{2}$ University of Basel, Switzerland, Basel., Switzerland; ${ }^{3}$ Trinity College, Dublin, Ireland; ${ }^{4}$ Nanyang Technological University; ${ }^{5}$ Bioprocessing Technology Institute, Singapore, Singapore

Background: Smoking has emerged as a consistent risk factor for ACPA positive RA, although the specific constituents of cigarette smoke that induce citrullination are unknown. It has been hypothesised that cadmium triggers RA as its inhalation links various well established risk factors for RA such as smoking (the most important environmental source of cadmium) and numerous working class occupations [1].

Objectives: To determine whether the cadmium-derived materials induce intracellular citrullination.

Methods: Human A549 lung epithelial cells were exposed to cadmium in ionic and particulate form represented by cadmium chloride and cadmium oxide, respectively, and their combinations with ultrafine carbon black (ufCB) nanoparticles produced following high temperature combustion, imitating cigarette burning Protein citrullination in cell lysates was analysed by SDS-PAGE electrophoresis with western blotting and verified by immunofluorescence staining and confocal microscopy. Target citrullinated proteins were identified by proteomic analysis. Results: Cytotoxicity studies demonstrated that cadmium compounds were toxic to the cells. Based on the results of cytotoxicity measurements, all the materials utilised in the experiments were subsequently applied to the cells in sub-toxic concentrations. Cadmium oxide, ufCB and its combination with cadmium chloride and cadmium oxide after high temperature combustion induced citrullination of multiple proteins in cultured human lung epithelial cells of A549 cell line, as demonstrated by SDS-SDS-PAGE electrophoresis and western blotting. This phenomenon develops via a peptidylargininedeiminase-dependent mechanism, as demonstrated in our previous studies [2]. The majority of citrullinated proteins were represented by the bands corresponding to the molecular weights between 55 and $72 \mathrm{kDa}$, and several less abundant bands at the level of $\sim 25 \mathrm{kDa}$ and over $130 \mathrm{kDa}$. Acidic cytokeratins of type I $(9,10)$ and basic/neutral cytokeratins type II $(1,2,5,6 \mathrm{~A}, 6 \mathrm{~B}$ and 77$)$ were identified as major intracellular citrullination targets. Immunofluorescent staining demonstrated that the citrullinated proteins were localised both in the cytoplasm and nuclei of cells exposed to cadmium particles, similar to the distribution patterns observed in cells exposed to ufCB.

Conclusions: Cadmium nanoparticle exposure facilitates post-translational citrullination of proteins.

References:

[1] Hutchinson D. Cadmium, one of the villains behind the curtain:has exposure to cadmium helped to pull the strings of seropositive rheumatoid arthritis pathogenesis all along? International journal of rheumatic diseases 2015;18:570-3.

[2] Mohamed BM, Verma NK, Davies AM, McGowan A, Crosbie-staunton K, Prina-Mello $A$, et al. Citrullination of proteins:a common post-translational modification pathway induced by different nanoparticles in vitro and in vivo. Nanomedicine 2012;7:1181-95

Acknowledgements: This work has been supported by the Higher Education Authority of Ireland, Science Foundation of Ireland through the Advanced Materials and BioEngineering Research (AMBER) project (Grant \#SFI/12/RC/2278) and the Cornwall Arthritis Trust.

Disclosure of Interest: None declared

DOI: 10.1136/annrheumdis-2017-eular.3620

\section{Spondyloarthritis - etiology, pathogenesis and animal models}

\section{AB0112 INTERFERON-REGULATED GENES (IRG) SIGNATURES DIFFERENTIATE GROUPS OF AS PATIENTS AND ARE ASSOCIATED WITH ANTI-TNF RESPONSE: PILOT DATA}

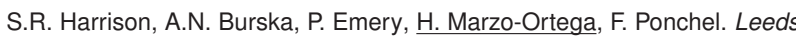
Institute of Rheumatic and Musculoskeletal Medicine, Leeds, United Kingdom

Background: Ankylosing Spondylitis (AS) is a chronic inflammatory arthritis characterised by sacroiliac/ lumbar spinal inflammation and extra-articular manifestations. Currently, TNF inhibitors (TNFi) are licensed for treatment-refractory AS; however, many patients do not respond to treatment and there is no way to predict Response/Non-Response (R/NR). The expression of several Interferon (IFN) signalling related genes (IRG) are associated with inflammatory diseases, including AS. Furthermore, an IRG expression signature has been used to predict treatment response in phase-la trials in systemic lupus erythematosus (1), demonstrating the feasibility of the use of IRG signatures as biomarkers in routine clinical practice.

Objectives: To explore whether IRG signatures differentiate groups of AS patients, and can be associated with response to TNFi in AS.

Methods: Twenty-six week-0 peripheral blood mononuclear cell (PBMC) samples

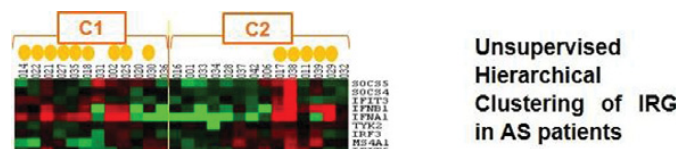

Red represents highe levels of gene expression and green represents lower levels of gene expression of the corresponding gene following

normalisation to the housekeeping gene, GAPDH. Clustering defined two groups (C1 and (2), driven by expression of the 14 IRG (blue box). Patient study numbers are listed at the top of the cluster. An orange dot adjacent to particular patient indicates that they were an ASDAS NR. 
from AS patients participating in a previously reported in-house clinical trial [infliximab (IFX), n=15 vs. placebo (P), n=11] (2) were selected from our tissue bank. R/NR was defined as a $\geq 1.1$ point reduction in AS Disease Activity Score (ASDAS) at week-30, or a reduction in the number of sacroiliac/vertebral MRI lesions. Expression of 96 IRG was quantified from PBMCs using custom TaqMan assays and analysed using unsupervised hierarchical clustering, Chi-Squared, and Mann-Whitney $U$ tests.

Results: A total of 11 patients were clinical responders [IFX=7/15; $P=4 / 11]$. At week-0, patients clustered into 2 groups (C1/C2) based on expression of 14 IRG. Clinical/demographic characteristics were not significantly different between $\mathrm{C} 1 / \mathrm{C} 2$ and groups were not biased for treatment $(\mathrm{C} 1, \mathrm{IFX}=8, \mathrm{P}=4 ; \mathrm{C} 2, \mathrm{IFX}=7$, $\mathrm{P}=7, \mathrm{p}=0.735$ ). Improvement in ASDAS was weakly associated with $\mathrm{C} 2$ (C2, $\mathrm{R}=8 / 14, \mathrm{C} 1, \mathrm{R}=7 / 12, \mathrm{p}=0.098)$. Looking at IFX treated patients only $(\mathrm{n}=15), 2$ cluster groups were observed (T1/T2) driven by 12 IRG. T2 was associated with a reduction in MRI lesions ( $T 2 R=6 / 7, T 1 \quad R=3 / 8, p=0.057$ ). Finally, paired week-0 and week-22 samples from 10 IFX-treated patients were analysed and clustered in 2 groups $(\mathrm{H} 1 / \mathrm{H} 2)$. Changes in IRG signature following treatment were observed towards segregating pre- and post- IFX treatment samples $(\mathrm{H} 1,6 / 8$ week- $0 ; \mathrm{H} 2$, $8 / 12$ week-22 $p=$ ?).

Conclusions: This pilot study suggests a possible association between IRG and response to IFX treatment in AS. These results now require assessment in a larger cohort in order to determine statistical and possible clinical significance, and to refine the signature further to construct potential predictive algorithms.

[1] Yao Y, et al. Arthritis Rheum 2009.

[2] Marzo-Ortega H, et al. Ann Rheum Dis 2005.

Acknowledgements: The authors would like to thank the George Drecler Foundation and BTCure EU/IMI for funding this project.

Disclosure of Interest: None declared

DOI: 10.1136/annrheumdis-2017-eular.4471

\section{AB0113 THE RELATIONSHIP OF POLYMORPHISMS OF ANTXR2 GENE WITH ANKYLOSING SPONDYLITIS IN CHINESE HAN}

Q. Lv, X. Wu, J. Gu. Third Affiliated Hospital of Sun Yat-Sen Universit, Guangzhou, China

Background: ANTXR2 as the protein binding to collagen IV and laminin, may be involved in extracellular matrix adhesion. GWAS study in European had found its SNPs has relationship with ankylosing spondylitis, but these variations were not related to Chinese people.

Objectives: In this study, we would find susceptibility locus in ANTXR2 associated with ankylosing spondylitis.

Methods: After the haplotype analysis from the 1000 Genomes Project data, we chose tags SNPs validated on 254 cases and 170 matched controls through Mass Spectrometry method. The patients were diagnosed accoding to the Modified New York Criteria for Ankylosing Spondylitis (1984).

Results: In 197 Chinese people from the 1000genome database, there are 16 Haplotype blocks of ANTXR2 gene. 5 SNPs were verified (rs78740643, rs11098964, rs28688624, rs4389526 and rs7689197) by mass spectrometry. Case/control association analysis showed rs11098964 having relationship with AS $(\mathrm{P}=0.01721$, OR $(95 \% \mathrm{Cl})=0.4793(0.2554-0.8621))$. Dominant model of rs11098964 were significant difference from controls $(P=0.0109)$.

Conclusions: our study found the rs11098964 also has relationship with AS. rs11098964 was protective against AS. ANTXR2 is related to susceptibility to AS References:

[1] Ng SC, Liao Z, Yu DT, Chan ES, Zhao L, Gu J. Epidemiology of spondyloarthritis in the People's Republic of China: review of the literature and commentary. Semin Arthritis Rheum 2007;37:39-47.

[2] Reveille JD, Sims AM, Danoy P, Evans DM, Leo P, Pointon JJ, et al. Genome-wide association study of ankylosing spondylitis identifies non-MHC susceptibility loci. Nat Genet 2010;42:123-7.

[3] Momenzadeh P, Mahmoudi M, Beigy M, Garshasbi M, Vodjdanian M, Farazmand A, et al. Determination of IL1 R2, ANTXR2, CARD9, and SNAPC4 single nucleotide polymorphisms in Iranian patients with ankylosing spondylitis. Rheumatol Int 2016;36:429-35.

[4] Guo C, Xia Y, Yang Q, Qiu R, Zhao H, Liu Q. Association of the ANTXR2 gene polymorphism and ankylosing spondylitis in Chinese Han. Scand J Rheumatol 2012;41:29-32.

[5] van der Linden S, Valkenburg HA, Cats A. Evaluation of diagnostic criteria for ankylosing spondylitis. A proposal for modification of the New York criteria. Arthritis Rheum 1984:27:361-8.

[6] Purcell S, Neale B, Todd-Brown K, Thomas L, Ferreira MA, Bender D, et al. PLINK: a tool set for whole-genome association and population-based linkage analyses. Am J Hum Genet 2007;81:559-75.

[7] Wu Z, Mou Y, Lin Z, Huang J, Wei Q, Gu J. HLA-B27 polymorphism in Han Chinese patients with ankylosing spondylitis: a distinctive disease association for B*2715 in a multiplex family. J Rheumatol 2009;36:2849-50.

[8] Goedecke V, Crane AM, Jaakkola E, Kaluza W, Laiho K, Weeks DE, et al. Interleukin 10 polymorphisms in ankylosing spondylitis. Genes Immun 2003:4:74-6.

[9] van der Paardt M, Crusius JB, Garcia-Gonzalez MA, Baudoin P, Kostense PJ, Alizadeh BZ, et al. Interleukin-1 beta and interleukin-1 receptor antagonist gene polymorphisms in ankylosing spondylitis. Rheumatology (Oxford) 2002;41:1419-23.

[10] Burton PR, Clayton DG, Cardon LR, Craddock N, Deloukas P, Duncanson A, et al. Association scan of 14,500 nonsynonymous SNPs in four diseases identifies autoimmunity variants. Nat Genet 2007;39:1329-37.

Disclosure of Interest: None declared

DOI: 10.1136/annrheumdis-2017-eular.4673

\section{AB0114 EFFECTS OF ANTI-IL17A BLOCKADE WITH SECUKINUMAB ON SYSTEMIC AND LOCAL IMMUNE RESPONSES: A MECHANISM- OF-ACTION STUDY IN PERIPHERAL SPONDYLOARTHRITIS}

L.J.J. Van Mens ${ }^{1}$, M.G. van de Sande ${ }^{1}$, S. Menegatti ${ }^{2}$, I.C.J. Blijdorp ${ }^{1}$, H.M. de Jong $^{1}$, I.A. Fluri ${ }^{1}$, T.E. Latuhihin ${ }^{1}$, A.W.R. van Kuijk ${ }^{3}$, N.G. Yeremenko ${ }^{1}$,

D.L. Baeten $1,4 .{ }^{1}$ AMC, Amsterdam Immunology and Rheumatology Center, Amsterdam, Netherlands; ${ }^{2}$ Immunology, Institut Pasteur, Paris, France; ${ }^{3}$ Reade, Amsterdam Immunology and Rheumatology Center, Amsterdam, Netherlands; ${ }^{4}$ UCB, Brussels, Belgium

Background: IL-17A blockade is an effective therapy for ankylosing spondylitis (AS) and psoriatic arthritis (PsA), the two prototypical forms of spondyloarthritis (SpA). How IL-17A blockade affects the systemic and local immune responses in $\mathrm{SpA}$ remains incompletely understood.

Objectives: To assess the effect of anti-IL17A treatment with secukinumab on the systemic cytokine responses and the synovial immunopathology in SpA patients with peripheral disease $(\mathrm{pSpA})$.

Methods: 20 active SpA patients were included in a 12wk open-label trial followed by 2yrs non-investigational extension. All patients received secukinumab $300 \mathrm{mg} / \mathrm{wk}$ from baseline to wk4 and then every $4 \mathrm{wks}$. Clinical response was measured 4wkly. TruCulture tubes with SEB and zymosan were drawn at baseline, day 3 , and wk12. Synovial biopsies were obtained by needle arthroscopy at baseline and wk12, analyzed by immunohistochemistry $(\mathrm{IHC})$ and qPCR.

Results: The $20 \mathrm{pSpA}$ patients consisted of 13 PsA, 3 undifferentiated SpA, 2 AS with peripheral arthritis, 1 reactive arthritis and 1 IBD associated pSpA. There were no SAEs in the 12 wk core study. However, two SAEs occurred in the extension of the study: tonsillitis (suspected to be related to study drug) and myocardial infarction (non related), both fully recovered. Secukinumab induced a rapid and highly significant improvement in SJC (Baseline: 2,5 [IQR1-4] vs wk12: 0,5 [IQR0-1]p $=0.001)$, TJC (6 [2-8] vs 0,5 [0-3]p $<0.001)$; VASptglobal (46 [28-65] vs $13[6-24] p<0.001) .18 / 20$ patients reached EULAR DAS response at wk 12 (10 good and 8 moderate responders). This was paralleled by significant improvements in other activity outcomes such as BASDAI (53 [25-63] vs 20 $[9-40] \mathrm{p}=0.001)$ and PASI $(5,7[4,5-7,1]$ vs $0,6[0,1-1,8] \mathrm{p}=0.001)$. Systemic inflammatory response revealed a decrease in CRP $(3,85[1,35-16,6]$ vs $2[1,15-$ $6,3] \mathrm{p}=0,001)$ and $\operatorname{ESR}(16[6-35]$ vs $6[2,8-16,3] \mathrm{p}=0,001)$, which was associated with decreased production of MMP-3, a validated biomarker of inflammation in pSpA, ${ }^{1}$ by peripheral blood cells in the TruCulture system (see figure). With exception of a decrease in IL-17A, the TruCulture system did not reveal any impact of secukinumab on the capacity of peripheral blood cells to produce a broad panel of cytokines and chemokines upon stimulation. In contrast with this preserved systemic immune response, IHC confirmed the positive impact of 12 wks of secukinumab on peripheral joint immunopathology as reflected by a significant decrease of infiltration of the synovial sublining with macrophages (2 [1-3] vs $1,5[1-2] \mathrm{p}=0.028)$ and neutrophils $(1[0,5-3,5]$ vs $0[0-1] \mathrm{p}=0.004)$, sensitive synovial biomarkers of treatment response in $\mathrm{pSpA} .^{2} \mathrm{mRNA}$ analysis of synovial biopsies before and after $12 \mathrm{wks}$ of secukimumab shows a decrease in IL-17A but not TNF expression.

Figure 1 - Reduction in secretion of IL-17 and MMP-3 in response to SEB in the whole blood TruCulture system after treatment with anti-IL17A.
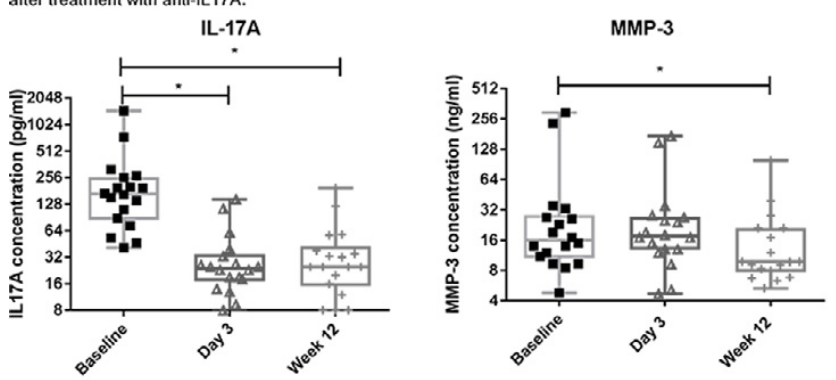

Significance of the comparisons is determined by a paired T-Test. Concentrations shown are pg/ml (IL-17) an $\mathrm{ng} / \mathrm{ml}$ MMP-3. P value $<0.05$ was considered significant and indicated with an (")

Conclusions: This mechanism-of-action study indicates that IL-17A blockade with secukinumab has a profound beneficial clinical and biological impact on pSpA without compromising systemic immune responses. Further gene expression analysis will delineate which inflammatory pathways are blocked by secukinumab in the diseased target tissue.

References:

[1] van Dooren, Arthritis \& Rheumatism, 2004

[2] Kruithof, Arthritis \& Rheumatism, 2005.

Disclosure of Interest: L. Van Mens: None declared, M. van de Sande Speakers 